\title{
História da Psicologia: (re)pensando objetos, métodos e discursos
}

\section{History of Psychology: (re)thinking about subjects, methods and discourses}

\section{Rodrigo Lopes Miranda*}

Universidade Federal de Minas Gerais - UFMG, Belo Horizonte, Minas Gerais, Brasil

ARAÚJO, S. F. (Org.). História e filosofia da psicologia: perspectivas contemporâneas. Juiz de Fora: Editora UFJF, 2012. 364p.

Contemporaneamente, podem ser observados discursos sobre a necessidade de produção de histórias da psicologia que sejam globais e locais (e.g. CIMINO, 2006; PICKREN; RUTHERFORD, 2012). Isso significa, por um lado, produzir histórias sobre a psicologia que observem as conexões entre os saberes psicológicos desenvolvidos em diferentes países. Por outro, implica em perceber que a psicologia foi produzida, localmente, a partir de circunstâncias próprias em cada país. A associação dessas duas visões permite notar aspectos culturais, sociais e institucionais, os quais participaram do desenvolvimento da psicologia, em diferentes localidades. Ela também possibilita observar semelhanças na produção da psicologia, nesses países. O esforço de pensar global e localmente a história da psicologia implica na necessidade de reflexão sobre seus objetos, métodos e discursos. É nesse quadro que pode ser inserida a obra História e Filosofia da Psicologia: Perspectivas Contemporâneas, organizada por Saulo de Freitas Araújo.

O livro possui doze capítulos, acrescidos de três textos iniciais: um Prefácio, de autoria de Marina Massimi; uma Apresentação, escrita pelo organizador e um texto reflexivo inicial, também de autoria de Saulo Araújo, que cumpre o papel de introduzir o campo interdisciplinar da História, da Filosofia e da Psicologia. Do total de capítulos, quatro foram escritos por pesquisadores vinculados a instituições brasileiras e os demais, por estudiosos de universidades de diversos países, tais como: Alemanha, Canadá, Espanha, Estados Unidos da América e Reino Unido. Se, por um lado, a presença marcante de autores estrangeiros na obra, auxilia na composição de uma articulação global-local; por outro, talvez para uma próxima 
produção, seja interessante um maior investimento em capítulos de autoria brasileira. Dessa forma, o leitor poderia acessar reflexões locais sobre as histórias da psicologia no País.

O conjunto da obra auxilia na observação da História e na Filosofia da Psicologia como áreas que requerem a coordenação de informações, com o objetivo de produzir relatos coerentes e interpretativos que consistem em tentativas de explicação, a partir da relação entre eventos. Os textos compreendem contribuições inéditas, bem como a tradução e a reprodução de artigos publicados alhures. Os capítulos abordam questões historiográficas gerais e, gradativamente, debruçam-se sobre temáticas específicas, tais como reflexões filosóficas sobre fundamentos teórico-conceituais da psicologia e análises sobre a produção psicológica nos séculos XVIII e XIX. O principal objetivo da obra é

[...] trazer para o público brasileiro estudos representativos na área da História e Filosofia da Psicologia, área que vem despertando cada vez mais interesse de pesquisadores, profissionais e estudantes de psicologia e áreas afins em nosso país (ARAÚJ O, 2012, p. 9).

De acordo com o organizador do livro, ele marca dois aspectos institucionais importantes. Primeiramente, constitui-se como um marco de fundação do Núcleo de Pesquisa em História e Filosofia da Psicologia (NUHFIP) da Universidade Federal de Juiz de Fora (UFJF). Em segundo lugar, ele documenta a criação da linha de pesquisa História e Filosofia da Psicologia do Programa de Pós-Graduação em Psicologia da UFJF [2]. A obra também pode ser inserida na produção e na organização de livros de membros do Grupo de Trabalho (GT) em História da Psicologia da Associação Nacional de Pesquisa e PósGraduação em Psicologia (ANPEPP), tal como o Dicionário Biográfico da Psicologia no Brasil (CAMPOS, 2001) e o Dicionário Histórico de Instituições de Psicologia no Brasil (JACÓ-VILELA, 2011). Com isso, nota-se a crescente produção em história da psicologia, no país, vinculada ao GT de História da Psicologia da ANPEPP.

A própria obra pode ser interpretada como um esforço de produção de reflexões, simultaneamente globais e locais, na história da psicologia. Ela apresenta capítulos que interpretam condições locais de produção da psicologia, bem como textos com reflexões mais ampliadas, gerais. O livro História e Filosofia da Psicologia: Perspectivas Contemporâneas auxilia a pensar que eventos locais são potencialmente relevantes para a história da psicologia. Ele também aponta para o fato de que essa história particular pode contribuir para pensar um quadro ampliado e, portanto, auxilia na produção de uma história global. Outro mérito do livro é que ele contribui para a pesquisa e para o ensino de Psicologia. A obra pode ser utilizada tanto para o ensino em graduação quanto em pós-graduação. Além 
disso, ela pode auxiliar em pesquisas na filosofia e na história da psicologia.

Um ponto de convergência entre os trabalhos localizados e os gerais é o interesse em pautar discussões sobre objetos, métodos e discursos da história da psicologia. Este aspecto pode ser observado em três exemplos de capítulos do livro. Primeiramente, o texto A História da Psicologia tem um objeto? de Roger Smith; em segundo lugar, o capítulo de Pickren e Rutherford, Rumo a uma história global da Psicologia e, por fim, o trabalho de Gundlach, A Psicologia como ciência e como disciplina: o caso da Alemanha. De acordo com Araújo (2012), tanto o texto de Smith quanto o de Pickren e Rutherford discutem "[...] questões metodológicas centrais para a história da psicologia" (p.13). O primeiro texto trata da suposta unicidade do objeto da "história da psicologia", enquanto o segundo afirma a importância de articular aspectos globais e locais na produção historiográfica da psicologia. O trabalho de Gundlach, por sua vez, apresenta uma reflexão sobre critérios que delimitam o surgimento da psicologia científica no século XIX. Nesse sentido, seu texto contribui para a recolocação da ideia de "psicologia como ciência", nos discursos historiográficos sobre a psicologia. De antemão, observam-se reflexões intercruzadas sobre objetos, métodos e discursos da história da psicologia na contemporaneidade.

Smith (2012) apresenta uma análise sobre o objeto da história da psicologia. Sua tese principal é de que inexiste "a" história da psicologia, uma vez que não é possível delimitar um objeto contínuo e unitário para estabelecer critérios para a produção dessa história. Ele propõe que a construção do objeto se dê durante o exercício historiográfico, no fazer com as fontes de pesquisa. $O$ fazer do pesquisador estará, então, sensível às especificidades do objeto que ele procura historicizar. Isso implica em considerar que a psicologia se diferencia a partir de condições locais específicas. Por exemplo, o desenvolvimento do behaviorismo ocorreu diferentemente no Brasil e nos Estados Unidos da América. Além disso, Smith afirma que o objeto historiográfico está, necessariamente, no cruzamento de interesses de dois tempos: passado e presente. De acordo com o autor, o objeto de uma história da psicologia pretende ser visto “[...] [como] uma atividade significativa do passado e como importante para a atividade de leitura e compreensão no presente" (SMITH, 2012 , p.43). Fica ampliada a ideia de "presentismo": por um lado, o historiador da psicologia deve evitar organizar e interpretar os materiais históricos a partir da perspectiva do presente. Por outro, cabe ao pesquisador considerar que o presente "[...] tem um papel estruturante naquilo que [...] escreve" (SMITH, 2012, p. 22). Assim, o autor parece sugerir que o historiador esclareça a que condições presentes ele responde e com as quais dialoga. Por exemplo, especificando a tese contra a qual ele se posiciona ou a favor de que 
argumento ele se apresenta. As proposições de Smith implicam no fato de que as narrativas, no campo da história da psicologia, devem ser múltiplas.

O trabalho de Pickren e Rutheford (2012) também é representativo desse movimento de conectar narrativas globais e locais. Em seu texto, eles apresentam tanto referências dos EUA, quanto autores indianos (e.g. Kapil Raj) e brasileiros (e.g. Ana Maria Jacó-Vilela, Marina Massimi e Regina Helena de Freitas Campos). Seu texto mantém a mesma linha de considerações sobre aspectos gerais da pesquisa historiográfica da psicologia. O principal mote desses autores é o que particulariza seu trabalho: "devemos ver o mundo como Norte e Sul, Leste e Oeste, se quisermos entender como a psicologia torna-se naturalizada em seus respectivos contextos nacionais e culturais" (PICKREN; RUTHERFORD, 2012, p.57). Essas histórias, localmente produzidas em conjunto, compõem um grande quadro compreensivo sobre a psicologia ao redor do mundo. Para a produção desses discursos historiográficos, os autores sugerem três possibilidades metodológicas: histórias profundas, histórias conectadas e historiografia feminista. As histórias profundas implicam na busca dos fundamentos culturais dos conhecimentos e fazeres psicológicos em cada país. As histórias conectadas implicam em considerar que, embora as práticas e aplicações da psicologia reflitam demandas situadas, o conhecimento psicológico tem de ser considerado em trânsito e, portanto, devem ser analisadas suas condições de transmissão. Por fim, a historiografia feminista exemplifica a consideração de novos objetos para a narrativa histórica da psicologia. Assim, Pickren e Rutheford discutem mais especificamente questões metodológicas contemporâneas postas para a historiografia da psicologia.

O trabalho de Smith (2012) reposiciona objetos para uma narrativa histórica, enquanto o de Pickren e Rutheford (2012) aborda, particularmente, os métodos de pesquisa. Por fim, o texto de Gundlach (2012) contribui para a reflexão sobre os discursos historiográficos da psicologia. Gundlach produz uma narrativa localizada sobre a psicologia, na Alemanha do século XIX. Porém, suas proposições colaboram para a mudança de narrativas na história da psicologia em outros países. Nesse processo, ele propõe alternativas para se conceber a Psicologia como campo do conhecimento, o que, por sua vez, impacta os discursos historiográficos sobre ela. Em sua concepção, a Psicologia pode ser considerada tanto "ciência", quanto "disciplina". De acordo com Gundlach, a "ciência" é a busca teórica, empírica ou experimental do conhecimento sobre o mundo. Supostamente, cada "ciência" possui objetos que delimitam sua especificidade. Ele continua, agora, sobre a "disciplina": 
[...] uma disciplina consiste em discípulos [...] e professores, em um corpo de conhecimento teórico e prático mais ou menos canônico [...], em passar nos exames, e na graduação do discípulo, após o exame final, que se torna um membro de uma classe socialmente reconhecida de pessoas, isto é, especialistas no campo de instrução ou na área de conhecimento em que foram treinados (GUNDLACH, 2012, p. 135)

Ser considerada de uma forma ou de outra irá impactar na seleção de fontes, nos objetivos e nas narrativas produzidas sobre a psicologia. Assim, pode-se escrever uma história sobre a Psicologia como ciência ou uma história sobre ela, como disciplina. Nesse processo, novas tramas precisam ser localizadas: disciplina associada a que áreas do conhecimento, com quais finalidades, com 0 uso de quais instrumentos, etc. O autor aponta que, ao serem discernidas as condições que contribuíram para a Psicologia como ciência daquelas que compuseram sua disciplinarização, pode-se alterar a célebre frase de Hermann Ebbinghaus [3] para "[...] a psicologia enquanto ciência tem um longo passado, mas a psicologia enquanto disciplina tem um passado bem curto [...]" (GUNDLACH, 2012, p. 159). Assim, as análises de Gundlach contribuem para a ampliação dos discursos históricos sobre a Psicologia, agora concebida ora como ciência, ora como disciplina.

A partir da leitura dessa obra, verifica-se que a filosofia da psicologia e a história da psicologia são áreas que, embora possuam suas especificidades, dialogam. O livro nos auxilia a colocar, em nova roupagem, as considerações de Josef Brozek (2001) sobre os ganhos no estudo da história da psicologia. De acordo com ele:

O estudo da história das ciências deve nos ensinar a virtude da modéstia. Além do mais, ajuda-nos a nos orientarmos de modo mais rápido e inteligente no presente e antecipar o futuro, mesmo que numa medida modesta (BROZEK, 2001, p.72).

O livro favorece a compreensão da história e da filosofia da psicologia, como áreas que contribuem para a formação e a atuação do psicólogo. Ele contribui para a leitura sobre o presente, a partir do conhecimento do passado. Auxilia a observar que o presente e 0 passado, embora particulares de cada localidade, podem dialogar. Por fim, ajuda no reconhecimento do presente como condição para a produção do futuro. Um futuro, especificamente, em que a história e a filosofia da psicologia sejam reconhecidas como discursos importantes, global e localmente. 


\section{Referências}

ARAÚJO, S. F. História e filosofia da psicologia: perspectivas contemporâneas. Juiz de Fora: Editora UFJ F, 2012. 364p.

BROZEK, J. Curso de Introdução à Historiografia da Psicologia: apontamentos para um curso breve. Memorandum: Memória e História em Psicologia, Belo Horizonte, v. 1, n.1, p. 72-78, 2001. Disponível em: <http://www.fafich.ufmg.br/ memorandum/artigos01/brozek01.htm $>$. Acesso em 04 out. 2012.

CAMPOS, R. H. F. Dicionário Biográfico da Psicologia no Brasil: Pioneiros. Rio de Janeiro: I mago e Conselho Federal de Psicologia, 2001. 461p.

CIMINO, G. Introduction: A comparative history of the birth of "scientific" psychology. Physis-Rivista I nternazionale di Storia della Scienza, Roma, v. 43, n.1-2, p. 1-30, 2006.

GUNDLACH, H. A Psicologia como ciência e como disciplina: o caso da Alemanha. In: ARAÚJO, S. F. (Org). História e filosofia da psicologia: perspectivas contemporâneas. Juiz de Fora: Editora UFJ F, 2012. p.133-165.

JACÓ-VILELA, A. M. Dicionário histórico de instituições de psicologia no Brasil. Rio de Janeiro: Imago Editora e Conselho Federal de Psicologia, 2011. 546p.

PICKREN, W.; RUTHERFORD, A. Rumo a uma história global da psicologia. In: ARAÚJO, S. F. (Org). História e filosofia da psicologia: perspectivas contemporâneas. Juiz de Fora: Editora UFJ F, 2012. p. 57-66

SMITH, R. A História da Psicologia tem um objeto? In: ARAÚJO, S. F. (Org). História e filosofia da psicologia: perspectivas contemporâneas. Juiz de Fora: Editora UFJF, 2012. p. 15-56.

\section{Endereço para correspondência \\ Rodrigo Lopes Miranda}

Av. Antônio Carlos, 6627. Faculdade de Educação. Universidade Federal de Minas Gerais. Pampulha. Belo Horizonte, Minas Gerais. CEP 30270-901.

Endereço eletrônico: dingoh@gmail.com

Recebido em: 25/10/2012

Aceito para publicação em: 02/01/2013

Acompanhamento do processo editorial: Ana Maria Jacó Vilela

\section{Notas}

* Mestre em Educação pelo Programa de Pós-Graduação em Educação da Faculdade de Educação da Universidade Federal de Minas Gerais. Doutorando pelo mesmo Programa. Bolsista de doutorado CAPES. Belo Horizonte, Brasil.

[1] Os autores agradecem às críticas e sugestões de Anna Christina Porto Maia Passarelli, Eustáquio José de Souza Júnior e Sérgio Dias Cirino. Todavia, quaisquer equívocos e imprecisões são de responsabilidade dos autores. 
[2] Uma entrevista com Saulo de Freitas Araújo sobre a criação do NUHFIP e da Linha de Pesquisa "História e Filosofia da Psicologia" pode ser encontrada aqui: <http://ripehp. wordpress.com/2012/02/06/entrevista-historia-e-filosofia-dapsicologia-na-ufjf-brasil/>. Acesso em 02 out. 2012.

[3] Hermann Ebbinghaus (1850-1909) é considerado um dos primeiros psicólogos experimentais alemães cujos trabalhos tinham relação com inteligência e memória. De acordo com Gundlach (2012), a célebre frase de que a psicologia tem um longo passado e uma curta história, é do capítulo Psychologie da obra Kultur der Gegenwart (A Cultura de Nosso Tempo). 